\title{
Equilibrium and kinetic fractionation on S-O clumping of sulfate
}

YUICHIRO UENO ${ }^{1,2,3^{*}}$, MAYUKO NAKAGAWA ${ }^{2}$, TOSHIKI KATSUTA $^{1}$, RIHO AOKI ${ }^{1}$, NAOHIRO YOSHIDA ${ }^{2,4}$

${ }^{1}$ Department of Earth and Planetary Sciences, Tokyo Institute of Technology, Meguro, Tokyo, 152-8551, Japan (*correspondence: ueno.y.ac@m.titech.ac.jp)

${ }^{2}$ Earth-Life Science Institute (WPI-ELSI), Tokyo Institute of Technology, Meguro, Tokyo, 152-8550, Japan

${ }^{3}$ Japan Agency for Marine-Earth Science and Technology (JAMSTEC), Natsushima-cho, Yokosuka 237-0061, Japan

${ }^{4}$ Department of Chemical Science and Engineering, Tokyo Institute of Technology, Yokohama, Kanagawa 226-8502, Japan

Sulfur and oxygen isotopes of sulfate have been used to trace biogeochemical processes through time. Potentially, doubly-substituted isotopologues of sulfate may provide unique additional information, though the measurement of isotopic clumping has been challenging. Recently, we have developed a $\mathrm{SO}_{2} \mathrm{~F}_{2}$ method to determine $\Delta^{34} \mathrm{~S}^{18} \mathrm{O}$ value, which represents relative abundance of ${ }^{34} \mathrm{~S}^{18} \mathrm{O}$ species against stochastic distribution, by using high-mass-resolution mass spectrometer (Katsuta et al. in this volume). In order to understand the potential fractionation processes, we have conducted a series of experiments. First, sulfate was synthesized by oxidation of $\mathrm{Na}_{2} \mathrm{SO}_{3}$ solution at various temperature. The results show that the $\Delta^{34} \mathrm{~S}^{18} \mathrm{O}$ value systematically decrease about $0.8 \%$ from $6^{\circ} \mathrm{C}$ to $120^{\circ} \mathrm{C}$. More negative $\Delta^{34} \mathrm{~S}^{18} \mathrm{O}$ can be observed when the sulfite was quickly oxidized and precipitated as $\mathrm{BaSO}_{4}$. The results suggest that the oxygen exchange between $\mathrm{SO}_{3}{ }^{2-}$ and $\mathrm{H}_{2} \mathrm{O}$ is responsible for changing the abundance of ${ }^{34} \mathrm{~S}-{ }^{18} \mathrm{O}$ bonding in the resulting sulfate, though additional kinetic effect should be accompanied during the oxidation step. Once the $\mathrm{SO}_{4}{ }^{2-}$ ion forms, the $\Delta^{34} \mathrm{~S}^{18} \mathrm{O}$ value seems to be quenched likely due to very slow exchange of oxygen with water. These results suggest that sulfate $\Delta^{34} \mathrm{~S}^{18} \mathrm{O}$ may not be utilized as a geothermometer for paleo-seawater, instead may be a tracer for distinguishing several key biogeochemical processes, including oxidative weathering and microbial sulfur metabolisms. 